\title{
Predicting vaccination using numerical and affective risk perceptions: The case of A/H1N1 influenza
}

\author{
Britta Renner*, Tabea Reuter \\ University of Konstanz, Germany
}

Keywords:

A/H1N1

Risk perception

Affect

Worry

Vaccination

\begin{abstract}
A B S T R A C T
During the 2009 A/H1N1 flu pandemic, German health authorities recommended vaccination; however the efficacy of such programs largely depends on individuals' risk perception. Risk perceptions are commonly determined through numerical-cognitive estimates such as the perceived likelihood and severity of the hazard. Instead, we argue that risk perceptions, which include more affect-related aspects such as worry and threat, are more powerful predictors of protective behaviors. Moreover, vaccines are often perceived as double-edged since they offer protection but also involve adverse side-effects. As such, in the context of the $A / H 1 N 1$ vaccine uptake, risk perception is not only disease-related (A/H1N1 infection) but also vaccine-related ( $A / H 1 N 1$ vaccine). The present longitudinal study was conducted during the runup to the German A/H1N1 vaccination campaign and measured cognitive and affective risk perceptions associated with both the $\mathrm{A} / \mathrm{H} 1 \mathrm{~N} 1$ infection and its vaccine ( $\mathrm{T} 1$, October $2009, N=397$ ) in order to assess their impact on (self-reported) A/H1N1 vaccination eight weeks later (T2, December $2009 ; N=285$ ). As assumed, greater perceived likelihood and severity of infection were associated with greater affective risk perception at $\mathrm{T} 1$. The more threatened and worried people felt, the more they intended to get vaccinated; however, the greater the perceived likelihood and severity of vaccine adverse side-effects, the greater the amount of vaccine related affective risk perception, impeding vaccination intention. Finally, vaccination intention predicted vaccination eight weeks later at $\mathrm{T} 2(\mathrm{OR}=2.2)$. The results suggest that numerical-cognitive risk perceptions, which are typically the target of public vaccination campaigns, do not impact preventive intention directly; instead, they facilitate affect-related risk perceptions, which motivate protective action.
\end{abstract}

\section{Introduction}

On June 11, 2009, the World Health Organization (WHO) declared the A/H1N1 pandemic [1]. Many governments, including Germany's, announced large-scale $\mathrm{A} / \mathrm{H} 1 \mathrm{~N} 1$ vaccination plans as a core part of national plans for pandemic mitigation $[2,3]$. In Germany, vaccination against A/H1N1 started on October 26, 2009 (week 44) with the monovalent $\mathrm{AS}_{03}$-adjuvantes $\mathrm{A} / \mathrm{H} 1 \mathrm{~N} 1$ vaccine Pandemrix ${ }^{\circledR}$ [3]. At the start of the vaccination campaign, when the present study was launched, the number of reported cases began to rise rapidly and the first increase in fatalities occurred [3]. By the end of November 2009 (week 47), the number of fatal cases had risen to a maximum of 37 [3] with more than $46,000 \mathrm{~A} / \mathrm{H} 1 \mathrm{~N} 1 \mathrm{new}$ cases that week [4]. The second peak, with 20 fatalities, occurred between the end of December 2009 and January 2010 (weeks 52 of 2009 to 1 of 2010) [4]. Although vaccination is the most effective intervention in preventing influenza [5] and $A / H 1 N 1$ vaccination

\footnotetext{
* Corresponding author. Tel.: +49 7531884679.

E-mail address: britta.renner@uni-konstanz.de (B. Renner).
}

was recommend by German health authorities, vaccine uptake in the general German population was very low. Only $6.8 \%$ of the general population above 14 years of age followed the recommendation to get vaccinated by April 2010 [6].

From a psychological perspective, the presence of an actual health risk such as an emerging influenza pandemic is not sufficient to trigger preventive behaviors such as vaccination. People need to believe that they are personally at risk in order to become motivated to protect themselves [7]. In health behavior theories, perceptions of self-related health risks are commonly conceptualized as numerical-cognitive beliefs which entail two components: (a) the perceived likelihood of the hazard and (b) the perceived seriousness of the hazard (e.g., A/H1N1 infection). Theoretically, perceptions of personal risk should be proportional to both; this implies that greater expected likelihood or severity results in greater overall perceived risk [8,9]. The motivational risk hypothesis assumes that the greater the cognitive-numerical risk perceptions are, the more likely people will be to take protective action $[8,10,11]$.

Cognitive-numerical risk perceptions such as perceived likelihood and severity might only represent a certain aspect of 
perceived risk [12-15]. According to the "risk-as-feelings" hypothesis, responses to risky situations result in part from emotional or affective influences, including feelings such as worry, fear, or threat [15]. Specifically, the risk-as-feelings conception assumes that affect mediates, at least in part, the relationship between an individual's cognitive evaluation of risk and their behavioral response to it [15]. Thus, numerical-cognitive risk perceptions might exert only an indirect effect on protective behavior through affect-related risk perceptions [15-18].

Previous studies examining the impact of both, cognitivenumerical and affective facets of risk perceptions have typically assessed risk perceptions within the context of well-known health hazards (e.g., cancer, seasonal flu infection). Since the respective hazard was no longer associated with immediate threat and the urgency to take precautions, it is possible that people had already digested the risk due to habituation effects $[19,20]$; thereby, resulting in comparably stable and affective "cooled-off" risk perceptions and beliefs about precautions. Conversely, when people are confronted with a new hazard, such as the A/H1N1 pandemic in 2009 . they are more likely to gauge their risk and consider changing their behavior in a relatively affective or "hot" mind set, allowing a more direct examination of the interplay between cognitive and affective risk perceptions.

Moreover, a new emerging hazard such as the swine flu pandemic not only represents an immediate health threat in comparison to well-known health threats such as smoking or lack of exercise, it also differs in terms of the consequences of the most effective prevention. Usually protective measures are perceived as being safe to conduct. In contrast, vaccines, the most effective measure for preventing influenza, may be seen as a health risk themselves. Thus, in the context of the new swine flu pandemic, two types of risk perceptions emerge: one is disease-related $(\mathrm{A} / \mathrm{H} 1 \mathrm{~N} 1$ infection) and the other one is vaccine-related (vaccine adverse side-effects). Cross-sectional studies comparing attitudes of $\mathrm{A} / \mathrm{H} 1 \mathrm{~N} 1$ vaccinated and unvaccinated respondents consistently showed that a perceived risk or concerns about adverse side-effects was the main reason for refusing $A / H 1 N 1$ vaccination $[2,11,21-23]$. However, a prospective study is required in order to examine whether the fear of side-effects actually prevents people from getting vaccinated or merely provides a retrospective explanation for their behavior.

The present study examined the relative impact of diseaserelated $(A / H 1 N 1$ infection) and vaccine-related $(A / H 1 N 1$ vaccine) risk perceptions on vaccination intention and self-reported receipt of $A / H 1 N 1$ vaccine. Moreover, the influence of different facets of risk perception on vaccination intention and behavior was assessed both for the virus and the adverse side-effects of the vaccine. According to the 'risk as feelings' hypothesis, we tested the indirect impact of numerical-cognitive perceived risk on vaccination intentions and vaccination through affective risk perceptions.

\section{Methods}

\subsection{Participants and procedure}

The first online survey (Time 1, T1) was conducted in October 2009 (weeks 43-44), just before the beginning of the vaccination campaign (week 44) and the peak of the swine flu epidemic in Germany (week 47). Using the snowball technique, participants were invited to the study via an official press release from the University of Konstanz (cf. [24-27] for a similar procedure). A sample of 397 participants completed the questionnaire at $\mathrm{T} 1$ and provided their e-mail addresses in order to receive an invitation for followup assessment at Time 2 (T2). Eight weeks later, in December 2009 (weeks 51-52), participants were asked to report whether they had been vaccinated against $\mathrm{A} / \mathrm{H} 1 \mathrm{~N} 1$.

The mean age of the total sample was 38 years $(S D=13.9$, $18-80$ years), and 251 (63.5\%) of the participants were women. The majority had a university entrance degree $(294=74.4 \%)$. More than half of the sample were employed $(221=57.4 \%$ ), in education $(124=32.2 \%)$, or retired $(22=5.7 \%)$. Of the $285(71.8 \%)$ participants who filled in the T2 questionnaire, 181 (64.0\%) were women $(M=38$ years, $S D=13.7,19-76$ years) and $73.2 \%$ had a university entrance degree. The study sample did not differ significantly from the dropout sample in terms of risk perceptions, $p>.12$; perceived severity, $p>.28$; intention to get vaccinated, $p>.50$; age $p>.52 ;$ sex, $p>.79$ or education, $p>.19$. At T2, 273 (95.8\%) of the 285 participants who filled in the $\mathrm{T} 2$ questionnaire reported their vaccination status ( $n=28 ; 9.8 \%$ received vaccination), and 283 out of 285 participants (99.3\%) reported whether they had been diagnosed with $A / H 1 N 1$ $(n=4,1.4 \%$ were diagnosed with $\mathrm{A} / \mathrm{H} 1 \mathrm{~N} 1)$.

Compared with German population data [28], the sample was four years younger, better educated ( $26 \%$ of the German population has a university entrance degree) and comprised of $12.5 \%$ more females. Moreover, in the sample, the employment rate $(51.3 \%$ German population) and the rate of participants in education was higher (4.8\% German population) and the retired rate lower $(20.1 \%$ German population).

\subsection{Measures}

\subsubsection{Cognitive disease-related risk perceptions}

Participants were asked to estimate (a) their absolute likelihood of becoming infected with $\mathrm{A} / \mathrm{H} 1 \mathrm{~N} 1$ influenza, with 1 (very unlikely) to 7 (very likely), and (b) their comparative likelihood of catching the virus in comparison to an average peer of their age and sex, with 1 (much below average), 4 (average), and 7 (much above average). The average score of the two items formed the index likelihood A/H1N1', with Cronbach's $\alpha=.70$. Furthermore, participants were asked to rate the severity of an A/H1N1 influenza infection with 1 (not serious/can be neglected), 4 (relatively serious, requires sick leave) and 7 (very serious/life threatening) (see also [29]).

Since the online-survey was conducted during the run-up to the German A/H1N1 flu vaccination campaign at the end of October 2009 , it is reasonable to assume that participants referred to the immediate risk even though the respective questions did not give a specific timeframe.

\subsubsection{Cognitive vaccine-related risk perceptions}

The perceived likelihood of adverse side-effects for the $A / H 1 N 1$ vaccine (VAE) was assessed by asking participants to estimate (a) their absolute likelihood of experiencing VAE, from 1 (very unlikely) to 7 (very likely), and (b) their comparative likelihood of experiencing VAE in comparison to an average peer of their age and sex, from 1 (much below average), 4 (average), and 7 (much above average). The two items were averaged to create an index likelihood VAE', with Cronbach's $\alpha=.71$. Furthermore, participants were asked to rate the severity of the vaccine's adverse side-effects on a 7-point scale, with 1 (not serious/can be neglected), 4 (relatively serious, requires sick leave) and 7 (very serious/life threatening) (see also [29]).

\subsubsection{Affective disease-related risk perceptions}

Participants were asked whether they were concerned about becoming infected with the $A / H 1 N 1$ virus and whether they felt threatened by the $A / H 1 N 1$ influenza using the item stem "I feel threatened/l am concerned ...", respectively. Answers ranged from 1 (completely disagree) to 4 (completely agree). Additionally, they were asked how worried they were about their health due to the swine flu, from 1 (not at all worried) to 7 (very worried). Due to 
Table 1

Pearson correlations between study variables (single items) at T1.

\begin{tabular}{|c|c|c|c|c|c|c|c|c|c|c|c|}
\hline & 2. & 3. & 4. & 5. & 6. & 7. & 8. & 9. & 10. & 11. & 12. \\
\hline $\begin{array}{l}\text { 1. Absolute likelihood } \\
\text { A/H1N1 } \\
(n=385)\end{array}$ & $\begin{array}{l}.54 \\
(.000)\end{array}$ & $\begin{array}{l}.18 \\
(.000)\end{array}$ & $\begin{array}{l}.14 \\
(.005)\end{array}$ & $\begin{array}{l}.16 \\
(.001)\end{array}$ & $\begin{array}{l}-.03 \\
(.542)\end{array}$ & $\begin{array}{l}.38 \\
(.000)\end{array}$ & $\begin{array}{l}.34 \\
(.000)\end{array}$ & $\begin{array}{l}.41 \\
(.000)\end{array}$ & $\begin{array}{l}.12 \\
(.023)\end{array}$ & $\begin{array}{l}-.01 \\
(.810)\end{array}$ & $\begin{array}{l}.26 \\
(.000)\end{array}$ \\
\hline $\begin{array}{l}\text { 2. Comparative likelihood } \\
\text { A/H1N1 } \\
(n=384)\end{array}$ & & $\begin{array}{l}.14 \\
(.005)\end{array}$ & $\begin{array}{l}.09 \\
(.094)\end{array}$ & $\begin{array}{l}.22 \\
(.000)\end{array}$ & $\begin{array}{l}-.06 \\
(.270)\end{array}$ & $\begin{array}{l}.28 \\
(.000)\end{array}$ & $\begin{array}{l}.23 \\
(.000)\end{array}$ & $\begin{array}{l}.33 \\
(.000)\end{array}$ & $\begin{array}{l}.10 \\
(.055)\end{array}$ & $\begin{array}{l}.03 \\
(.594)\end{array}$ & $\begin{array}{l}.23 \\
(.000)\end{array}$ \\
\hline $\begin{array}{l}\text { 3. Severity A/H1N1 } \\
(n=384)\end{array}$ & & & $\begin{array}{l}.03 \\
(.554)\end{array}$ & $\begin{array}{l}.10 \\
(.056)\end{array}$ & $\begin{array}{l}.14 \\
(.005)\end{array}$ & $\begin{array}{l}.37 \\
(.000)\end{array}$ & $\begin{array}{l}.31 \\
(.000)\end{array}$ & $\begin{array}{l}.37 \\
(.000)\end{array}$ & $\begin{array}{l}.12 \\
(.021)\end{array}$ & $\begin{array}{l}-.09 \\
(.079)\end{array}$ & $\begin{array}{l}.15 \\
(.002)\end{array}$ \\
\hline $\begin{array}{l}\text { 4. Absolute likelihood VAE } \\
(n=383)\end{array}$ & & & & $\begin{array}{l}.58 \\
(.000)\end{array}$ & $\begin{array}{l}.39 \\
(.000)\end{array}$ & $\begin{array}{l}.11 \\
(.026)\end{array}$ & $\begin{array}{l}.10 \\
(.048)\end{array}$ & $\begin{array}{l}.16 \\
(.001)\end{array}$ & $\begin{array}{l}.55 \\
(.000)\end{array}$ & $\begin{array}{l}46 \\
(.000)\end{array}$ & $\begin{array}{l}-.04 \\
(.478)\end{array}$ \\
\hline $\begin{array}{l}\text { 5. Comparative likelihood } \\
\text { VAE } \\
(n=382)\end{array}$ & & & & & $\begin{array}{l}.27 \\
(.000)\end{array}$ & $\begin{array}{l}.17 \\
(.001)\end{array}$ & $\begin{array}{l}.12 \\
(.022)\end{array}$ & $\begin{array}{l}.21 \\
(.000)\end{array}$ & $\begin{array}{l}.37 \\
(.000)\end{array}$ & $\begin{array}{l}.29 \\
(.000)\end{array}$ & $\begin{array}{l}.04 \\
(.426)\end{array}$ \\
\hline $\begin{array}{l}\text { 6. Severity VAE } \\
\qquad(n=382)\end{array}$ & & & & & & $\begin{array}{l}.09 \\
(.095)\end{array}$ & $\begin{array}{l}.18 \\
(.000)\end{array}$ & $\begin{array}{l}.17 \\
(.001)\end{array}$ & $\begin{array}{l}.53 \\
(.000)\end{array}$ & $\begin{array}{l}.54 \\
(.000)\end{array}$ & $\begin{array}{l}-.19 \\
(.000)\end{array}$ \\
\hline $\begin{array}{l}\text { 7. Concern A/H1N1 } \\
(n=386)\end{array}$ & & & & & & & $\begin{array}{l}.76 \\
(.000)\end{array}$ & $\begin{array}{l}.69 \\
(.000)\end{array}$ & $\begin{array}{l}.24 \\
(.000)\end{array}$ & $\begin{array}{l}.03 \\
(.567)\end{array}$ & $\begin{array}{l}.43 \\
(.000)\end{array}$ \\
\hline $\begin{array}{l}\text { 8. Threat A/H1N } 1 \\
(n=385)\end{array}$ & & & & & & & & $\begin{array}{l}.67 \\
(.000)\end{array}$ & $\begin{array}{l}.26 \\
(.000)\end{array}$ & $\begin{array}{l}.11 \\
(.038)\end{array}$ & $\begin{array}{l}.30 \\
(.000)\end{array}$ \\
\hline $\begin{array}{l}\text { 9. Worry A/H1N } 1 \\
(n=385)\end{array}$ & & & & & & & & & $\begin{array}{l}.27 \\
(.000)\end{array}$ & $\begin{array}{l}.08 \\
(.120)\end{array}$ & $\begin{array}{l}.39 \\
(.000)\end{array}$ \\
\hline $\begin{array}{l}\text { 10. Fear VAE } \\
(n=385)\end{array}$ & & & & & & & & & & $\begin{array}{l}.71 \\
(.000)\end{array}$ & $\begin{array}{l}-.07 \\
(.188)\end{array}$ \\
\hline 11. Comparative fear VAE & & & & & & & & & & & -.26 \\
\hline $\begin{array}{l}\text { vs. H1N1 } \\
(n=386)\end{array}$ & & & & & & & & & & & $(.000)$ \\
\hline $\begin{array}{l}\text { 12. Vaccination intention } \\
(n=381)\end{array}$ & & & & & & & & & & & \\
\hline
\end{tabular}

Note: VAE, vaccine adverse effect. Numbers at the top refer to variables' names in the left column. Statistically significant correlation coeficients are displayed in bold and $p$-values are given in parentheses.

different scale formats, all three variables were $z$-standardized before they were averaged for the index 'Affective A/H1N1 risk', Cronbach's $\alpha=.83$.

\subsubsection{Affective vaccine-related risk perceptions}

Participants were asked whether they were afraid of the sideeffects of the A/H1N1 vaccine and whether they were afraid that the side effects of the vaccine would be worse than the infection itself. Answers ranged from 1 (completely disagree) to 4 (completely agree), Cronbach's $\alpha=.83$.

\subsubsection{Vaccination intention}

Participants were asked if they intended to receive vaccination on a 7-point scale, with 1 (not at all) and 7 (very strongly).

\subsubsection{Self-reported vaccination}

In the follow-up survey at T2, participants were asked whether they had received an $A / H 1 N 1$ vaccine, with 0 (no) and 1 (yes).

Table 1 shows the Pearson correlations between all variables.

\subsection{Analyses}

First, mean level changes in risk perceptions were analyzed using MANOVA for repeated measures. To determine the effect sizes of the observed mean difference between variables, the effect size index Cohen's $d[30]$ was calculated. Cohen has defined the following effect size conventions for $d$ : small $d=.2$, medium $d=.5$, and large $d=.8$. Missing values were treated by listwise deletion, and therefore, the results are based on a varying number of cases. Pearson correlations were calculated for analyzing bivariate relations between study variables. For analyzing baseline characteristics of the participants as a function of vaccine uptake, logistic regressions were calculated and $95 \%$ confidence intervals for $\log (O R)$ were estimated using bootstrapping. Finally, the main study hypothesis was tested with a path model employing logistic regression analysis using Mplus Version 5.2. For path modeling, full information maximum likelihood estimation (FIML [31]) was employed to derive parameter estimates in the face of missing data; FIML makes use of all available data in model estimation. To estimate indirect effects, a non-parametric bootstrapping approach was employed [32]. The present analyses are based on a new mediation approach [33,34], using bootstrapping, which does not require that $X$ and $\mathrm{Y}$ are directly associated. In order to differentiate between the two approaches, we use the term 'indirect effects' [33] for results based on bootstrapping. Logistic regression coefficients for indirect effects were estimated using a Newton-Raphson iteration algorithm [32]. Vaccination uptake served as the dependent variable with $1=$ vaccination and $0=$ no vaccination.

\section{Results}

\subsection{Cognitive and affective risk perceptions}

\subsubsection{Perceived comparative likelihood}

When the vaccine became available in October 2009 (T1), participants perceived their own likelihood of becoming A/H1N1infected in comparison to an average peer of their age and sex as significantly lower (perceived comparative likelihood of becoming $A / H 1 N 1$-infected with $M=3.6, S D=1.23$ vs. scale midpoint of $4.0, t(383)=6.16, p<.001)$. The mean of the perceived comparative likelihood judgements, if it had been unbiased, should have fallen at the midpoint of the scale (i.e., at "average" with a value of 4.0 ). Because the average risk cannot be below the mean, this finding represents an optimistic bias at the level of the group (cf. $[7,8])$. Turning to vaccine-related risk perceptions shows that participants believed that their risk of suffering from adverse vaccine side-effects was lower in comparison to their peers (comparative likelihood of becoming $\mathrm{A} / \mathrm{H} 1 \mathrm{~N} 1$-infected with $M=3.8 . S D=1.27$ vs. scale midpoint $=4.0, t(381)=3.07, p=.002$ ), indicating a small, albeit significant, optimistic bias. 


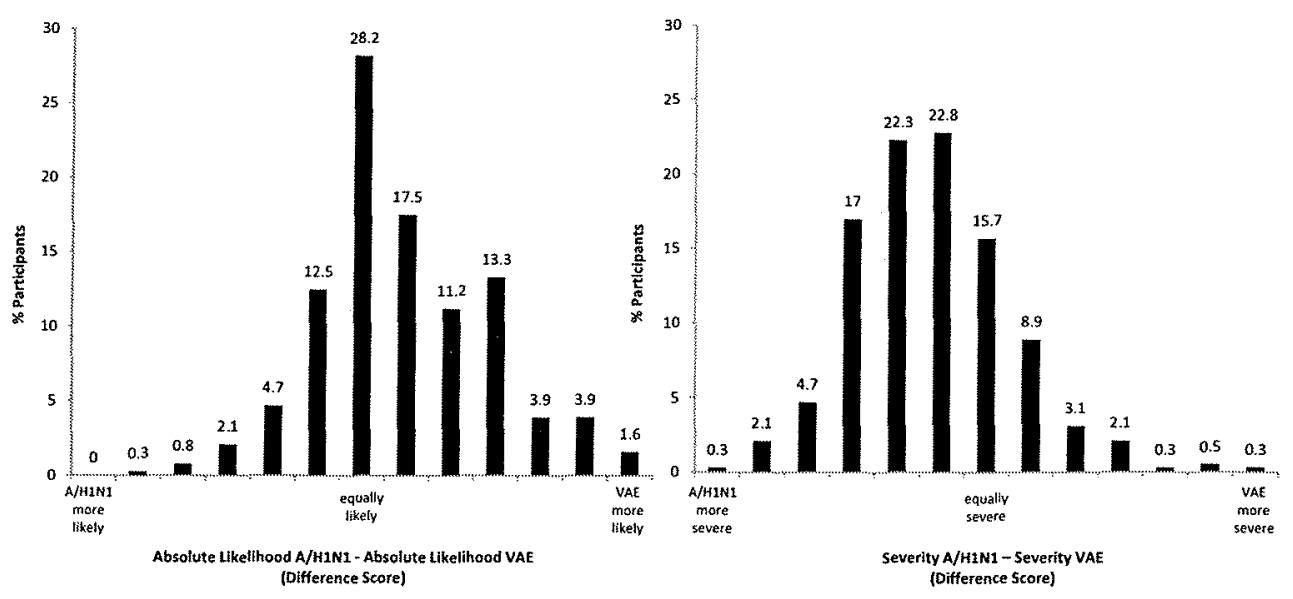

Fig. 1. Difference score between $A / H 1 N 1$ and VAE absolute likelihood ratings (left) and difference score between perceived $A / H 1 N 1$ and VAE severity (right).

\subsubsection{Perceived absolute likelihood}

Comparing the perceived absolute likelihood of becoming infected with $\mathrm{A} / \mathrm{H} 1 \mathrm{~N} 1$ with the perceived absolute likelihood of suffering from vaccine adverse side-effects (VAE) shows that, on average, participants found it more likely that they would suffer from vaccine adverse side-effects (VAE) than become infected with the virus (absolute likelihood VAE: $M=3.8, S D=1.71 \mathrm{vs}$. absolute likelihood $\mathrm{A} / \mathrm{H} 1 \mathrm{~N} 1: M=2.9, S D=1.24 ; t(382)=9.17 ; p<.001$, Cohen's $d=60$ ). A comparison between the VAE and A/H1N1 likelihood rating within each respondent, calculated by a difference score, showed that $52 \%$ of the participants $(n=197)$ believed that it was more likely that they would suffer from vaccine adverse side-effects than become infected with the virus. Moreover, $28 \%$ $(n=108)$ believed that the two likelihoods were comparable, and only $20 \%$ of the participants $(n=78)$ believed that an $\mathrm{A} / \mathrm{H} 1 \mathrm{~N} 1$ infection was more likely than suffering from vaccine adverse sideeffects (see Fig. 1).

\subsubsection{Perceived severity}

On average, adverse vaccine side-effects were seen as being less severe than an $A / H 1 N 1$ infection (perceived severity of VAE $M=3.1$, $S D=1.42$ vs. perceived severity of an $A / H 1 N 1$ influenza infection: $M=4.3, S D=1.31 ; t(381)=13.39, p<.001$, Cohen's $d=.88)$. Calculating a difference score showed that $69 \%$ of the participants $(n=204)$ rated an $\mathrm{A} / \mathrm{H} 1 \mathrm{~N} 1$ infection as being more severe than the vaccine adverse side-effects, $16 \%(n=60)$ rated them as equally severe, and $15 \%(n=58)$ rated the severity of an A/H1N1 infection as being lower (see Fig. 1).

\subsubsection{Affect-related risk perceptions}

Reported worry due to an A/H1N1 infection was relatively low $(M=2.3 ; S D=1.25)$. Moreover, on average participants were only somewhat concerned or threatened by the $\mathrm{A} / \mathrm{H} 1 \mathrm{~N} 1$ influenza $(M=1.8, S D=.77$ and $M=1.6, S D=.68)$. Affective risk perceptions related to vaccine adverse side-effects were more pronounced. Mean reported anxiety of adverse side-effects $(M=2.4, S D=.99)$ was significantly greater than concern, $t(384)=10.17, p<.001$ or felt threat due a $A / H 1 N 1$ infection $t(384)=15.73, p<.001$. In addition, participants were moderately afraid that the side effects of the $A / H 1 N 1$ vaccine would be worse than the $A / H 1 N 1$ infection itself $(M=2.2, S D=1.08)$, whereby $43 \%$ stated that they were more afraid of VAE than of an $A / H 1 N 1$ infection and $57 \%$ stated that they were more afraid of an $A / H 1 N 1$ infection than of VAE.

\subsection{Vaccination intention at $T 1$ and vaccination status at $T 2$}

Three hundred and eighty one ( $96 \%$ ) of the 397 participants who completed the T1 survey in October 2009 responded to the question of whether they intended to have the $\mathrm{A} / \mathrm{H} 1 \mathrm{~N} 1$ vaccination. Seventy-two percent $(274 / 381$ ) reported that they did not intend to get vaccinated (items rating score 1 and 2 ) and only $4.8 \%(22 / 381$ ) reported a very strong intention to get vaccinated (items score 6 and 7).

Table 2 summarizes the baseline characteristics of the participants as a function of vaccine uptake. Within the longitudinal sample, 28 of the 273 participants who stated their vaccination status reported having received the $\mathrm{A} / \mathrm{H} 1 \mathrm{~N} 1$ vaccination (9.8\%). Participants under 25 years of age were less likely to get vaccinated than those over, and participants diagnosed with $\mathrm{A} / \mathrm{H} 1 \mathrm{~N} 1$ infection at $\mathrm{T} 1$ were less likely to report being vaccinated. No differences in vaccination status in dependence of gender or education were observed.

\subsection{Who received $A / H 1 N 1$ vaccine? Cognitive and affective risk perceptions predicting vaccination intention (T1) and vaccination (T2)}

Vaccination at $\mathrm{T} 2$ was significantly predicted by the intention to get vaccinated at $\mathrm{T} 1$ with the odds ratio $[\mathrm{OR}]=2.22,95 \%$ and the confidence interval $[\mathrm{CI}]=1.75-2.82$. In turn, the intention to get vaccinated at $\mathrm{T} 1$ was only predicted by affective disease- and vaccine-related risk perceptions, which were in turn associated with cognitive risk perceptions (cf. Fig. 2).

First, the more worried, concerned, and threatened people felt by the $A / H 1 N 1$ infection, the greater their vaccination intention $(\beta=.35, p<.001)$. Conversely, and as expected, the more participants were afraid of potential side-effects, the lower their vaccination intention $(\beta=-.28, p<.001)$. Moreover, a significant interaction between affective disease- and vaccine-related risk perceptions was observed $(\beta=-.17, p<.01)$. In total, $24 \%$ of the variance in vaccination intention was explained by these variables.

Second, both affective disease- and vaccine-related affective risk perceptions were related to numerical-cognitive risk perceptions. Specifically, the perceived likelihood $(\beta=.38, p<.001)$ and severity of an $A / H 1 N 1$ infection $(\beta=.33, p<.001)$ and their interaction $(\beta=.18, p<.001)$ were associated with a higher disease-related affective risk perception, explaining $31 \%$ of the variance.

For estimating the specific indirect effects for perceived likelihood and perceived severity of an A/H1N1 infection, a 
Table 2

Baseline characteristics of participants at $\mathrm{T} 1$ as a function of $\mathrm{A} / \mathrm{H} 1 \mathrm{~N} 1$ vaccination status at $\mathrm{T} 2$.

\begin{tabular}{|c|c|c|c|}
\hline & Vaccinated $n(\%)$ & Unvaccinated $n(\%)$ & $\log (O R)(95 \%-C l)$ \\
\hline \multicolumn{4}{|l|}{ Age group $(n=270)$} \\
\hline$<25$ & $2(7)$ & $55(23)$ & Ref. \\
\hline $25-45$ & $13(46)$ & $106(44)$ & $1.22(.04-19.4)$ \\
\hline$\geq 46$ & $13(46)$ & $81(33)$ & $.27(-.57$ to 1.18$)$ \\
\hline \multicolumn{4}{|l|}{$\operatorname{Sex}(n=271)$} \\
\hline Female & $12(44)$ & $159(65)$ & Ref. \\
\hline Male & $15(56)$ & $85(35)$ & $.85(-.05$ to 1.76$)$ \\
\hline \multicolumn{4}{|l|}{ Education $(n=271)$} \\
\hline No university entrance degree & $20(71)$ & $178(73)$ & Ref. \\
\hline University entrance degree & $8(29)$ & $67(27)$ & $.06(-1.13$ to .95$)$ \\
\hline \multicolumn{4}{|l|}{ Cases diagnosed with A/H1N1 $(n=272)$} \\
\hline Cases not diagnosed with $\mathrm{A} / \mathrm{H} 1 \mathrm{~N} 1$ & $28(100.0)$ & $240(98)$ & Ref. \\
\hline Cases diagnosed with $\mathrm{A} / \mathrm{H} 1 \mathrm{~N} 1$ & $0(0.0)$ & $4(2)$ & $-19.05(-19.44$ to -18.57$)$ \\
\hline
\end{tabular}

Note: $\log (\mathrm{OR}), \log$ odds ratio; $\mathrm{Cl}$, confidence interval (bootstrap based).

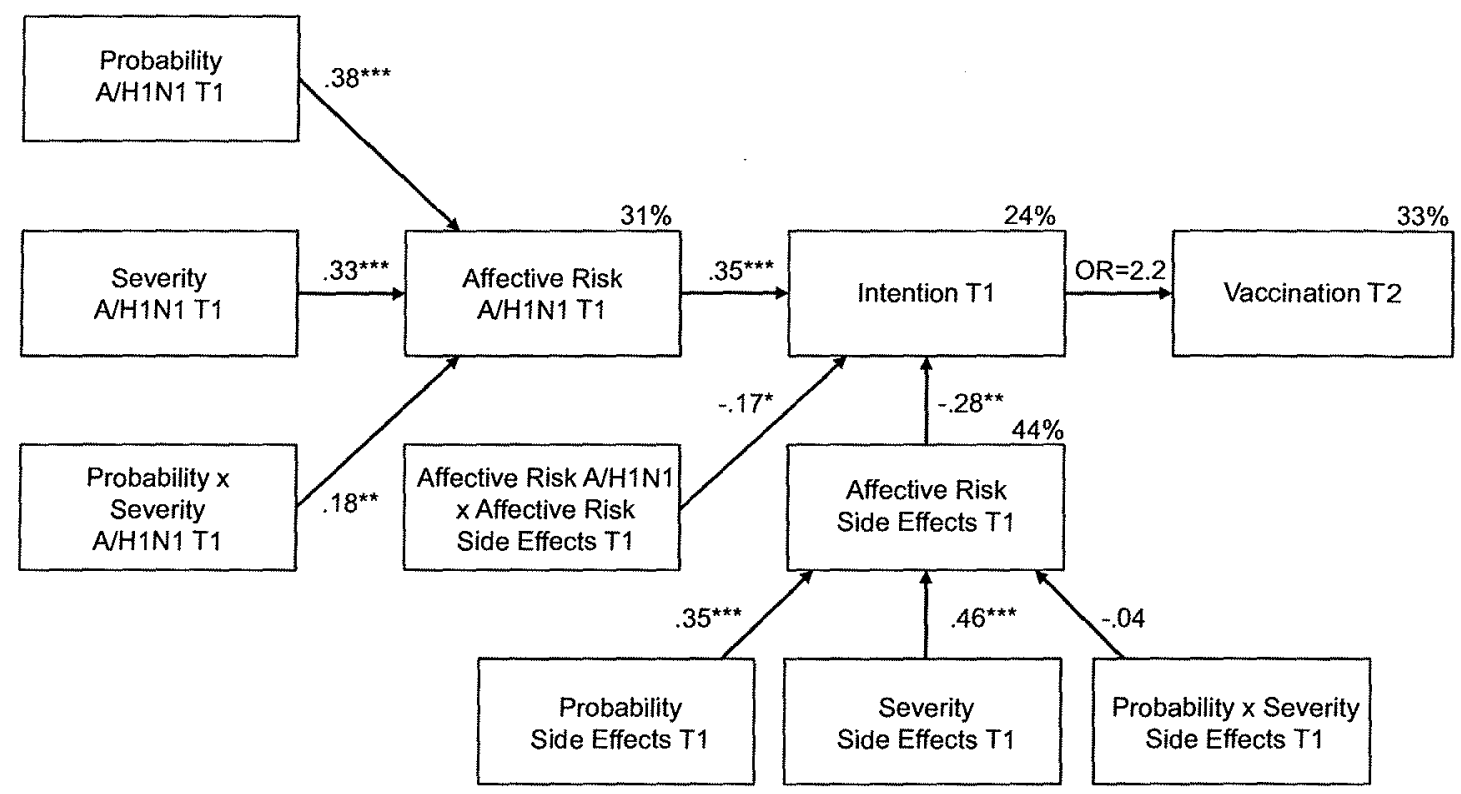

Fig. 2. Path model of the relationship between vaccination (T2), vaccination intention (T1), and disease-related and vaccine-related risk perceptions (T1).

non-parametric bootstrapping approach recommended by Preacher and Hayes [32] was employed. The bootstrapping approach yielded a significant positive indirect effect of numerical-cognitive risk perceptions on vaccination through affective risk perceptions and intention (perceived likelihood $=.04, \quad 95 \%-\mathrm{Cl}=.01-.07 ; \quad$ severity $=.02, \quad 95 \%-\mathrm{Cl}=.01-.04$; likelihood $\times$ severity $=.02,95 \%-\mathrm{Cl}=.01-.05$ )

The same was true for cognitive vaccine-related risk perceptions, though, as expected, with the opposite effect on intention and vaccination. The more likely vaccine adverse sideeffects were perceived to be $(\beta=.35, p<.001)$ and the more severely they were rated $(\beta=.46, p<.001)$, the more pronounced the affective risk perceptions related to the vaccine, explaining $44 \%$ of the variance. The indirect effects of vaccine-related numerical-cognitive risk perception on vaccination through affective risk perception and intention were negative and significant, except for the likelihood $\times$ severity interaction (perceived likelihood $=-.04,95 \%-\mathrm{Cl}=-.07$ to -.02 ; severity $=-.06,95 \%-\mathrm{Cl}=-.10$ to -.03 ; likelihood $\times$ severity $=.01,95 \%-\mathrm{Cl}=-.002$ to .03 ). Although significant bivariate relationships between perceived cognitivenumerical risk perceptions and vaccination intention were found (index perceived likelihood A/H1N1/intention: $r=.28, p<.001$; but index perceived likelihood VAE/intention: $r=.01, p=.96$; perceived severity $\mathrm{A} / \mathrm{H} 1 \mathrm{~N} 1 /$ intention: $r=.15, p=.002$; perceived severity VAE/intention: $r=-.19, p<.001$ ), the direct effects of numericalcognitive risk perceptions on vaccination intention in the model were not significant (all $\beta<.07$, all $p<.13$ ).

\subsubsection{Control analysis}

In order to secure the found pattern of results, the model was additionally tested within subgroups of the sample which can be characterized as being more 'anti-vaccine' or as being more 'provaccine' based on the difference score between absolute likelihood ratings for $A / H 1 N 1$ and $\operatorname{VAE}$ (see also Fig. 1, left side). Within the subsample who believed that it was more likely that they would suffer from vaccine adverse side-effects than become infected with the virus ( $n=197$, 'anti-vaccine group'), affective risk perception for A/H1N1 $(\beta=.34, p<.001)$ and for VAE $(\beta=-.27, p<.001)$ and their interaction term $(\beta=-.14, p=.05)$ predicted vaccination intention with $R^{2}=30$. Similar results were found for the subgroup who believed that an $A / H 1 N 1$ infection was equally or more likely than suffering from $\operatorname{VAE}(n=186$, 'pro-vaccine group') with affective risk perception for $A / H 1 N 1(\beta=.29, p<.001)$, for $\operatorname{VAE}(\beta=-.19, p<.01)$ and their interaction term $(\beta=-.19, p<.01)$ predicted vaccination 


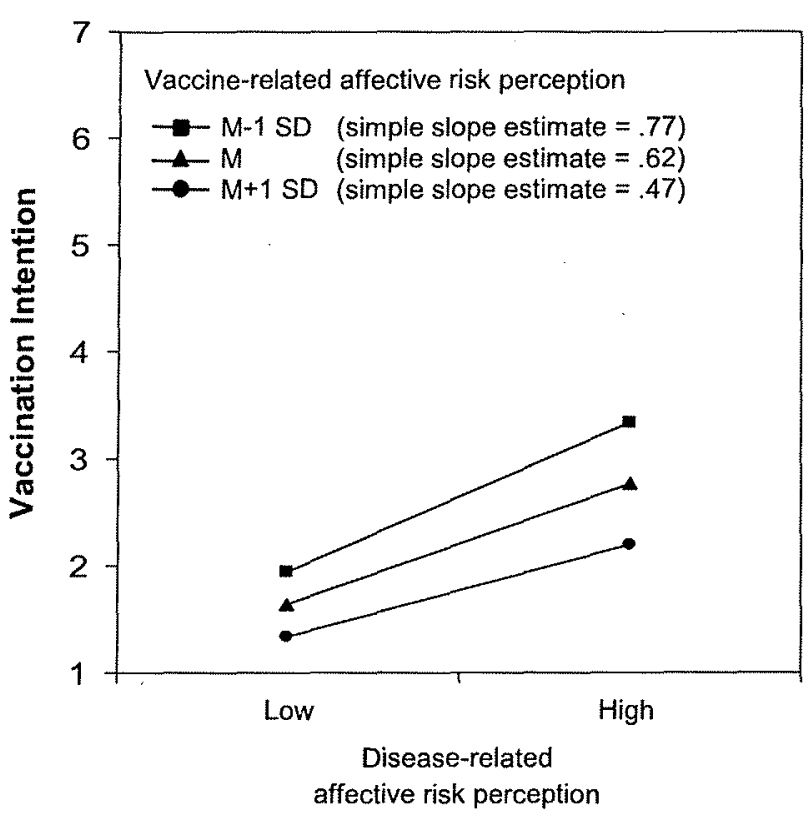

Fig. 3. Estimated direct effects of disease-related risk perception on vaccination intention at different values of affective vaccine-related risk perception.

intention with $R^{2}=27$. A similar pattern of results emerged when the sample was divided based on the severity difference score (see also Fig. 1, right side). Affective risk perception explained 39 percent of the vaccination intention within participants who believed that adverse vaccine side-effects were more severe than an $\mathrm{A} / \mathrm{H} 1 \mathrm{~N} 1$ infection ( $n=58$, 'anti-vaccine group') and 28 percent of the vaccination intention within participants who believed that an $A / H 1 N 1$ infection was equally or more severe than $\operatorname{VAE}(n=324$, 'pro-vaccine group').

\subsection{Probing the interaction between disease-and vaccine-related affective risk perceptions}

Following Aiken and West [35], we characterized the interaction by estimating the regression of vaccination intention on affective disease-related risk perceptions as a function of affective vaccinerelated risk perceptions. We examined the simple regression of vaccination intention on affective disease-related risk perceptions at three values of affective vaccine-related risk perceptions, which represent approximate values of the mean $(M)$ with $M, M-1 S D$, $M+1 S D$, respectively, and tested the significance of the simple slope at each value. The estimated simple slopes for $M+1 S D, M$, and $M-1 S D$ for affective vaccine-related risk perception (.47, $p<.05$, .62 , and .77 , both $p<.001$ ) became increasingly positive and statistically significant, as shown in Fig. 3. Thus, participants developed the highest vaccination intention when disease-related affective risk perceptions were high and vaccine-related affective risk perceptions were low. However, when disease-related affective risk perceptions were low, affective vaccine-related risk perceptions had no substantial effect on vaccination intention.

\section{Discussion}

In the run-up to the German $\mathrm{A} / \mathrm{H} 1 \mathrm{~N} 1$ flu vaccination campaign at the end of October 2009, only a small number of participants had a very strong intention to receive the vaccine. Eight weeks later, in December 2009 , the vaccination uptake for both the present sample (9.8\%) and the German population in general $(6.8 \%[3] ; 8.1 \%[6])$ was low. Considering that only $17 \%$ of the 1000 German interviewees in the Flash Eurobarometer survey FL287 - influenza A/H1N1 strongly supported the idea that vaccination was an effective measure against the virus, a low vaccination rate was to be expected [36].

The data suggest that the likelihood of being vaccinated was determined by the vaccination intention, which in turn was modulated by the interplay between affective disease- and vaccinerelated risk perceptions. Conversely, cognitive risk perceptions such as the perceived likelihood and severity of an A/H1N1 infection or adverse side-effects only indirectly impacted vaccination intention through affective risk perceptions.

The present data suggest a sequence from thoughts to feelings to protective behaviors: greater numerical-cognitive perceived risk was associated with greater affective risk perception which impacted vaccination intention and behavior. Thus, the disease as well as the adverse vaccine effects might have triggered a sequence from rather "cold" numerical-cognitive risk perceptions to "hot" affective risk perceptions, which in turn impacted on vaccination intention. We found a similar pattern of results in a different sample and with a different preventive behavior i.e., the pick-up rate of a free bottle of hand sanitizer at the end of the first swine flu pandemic wave in December 2009 [24], pointing to the reliability of the present findings. Accordingly, cognitive risk perceptions exert their impact on behavioral proximal variables through affective risk perceptions. Thus, studies which observed no significant relation between the perceived likelihood and severity of an A/H1N1 infection and vaccination intention [2] or status [22] do not necessarily imply that disease-related risk perceptions do not matter, but rather, that they are not sufficient. Numerical risk representations might often be perceived as an abstract information with only limited vividness and experiential value $[13-15,37,38]$. Our results indicate that these cognitive, numerical representations of risk need to be translated into a more vivid, self-related, and affectladen form of risk perception such as worry in order to become motivationally relevant. Abstract numerical risk representations might therefore not impact protective behavior directly but might trigger a more experiential or 'visceral' mode of risk perception, such as worry, which in turn increases protective behavior.

Although vaccination is a very powerful preventive measure, fear of adverse side-effects may prevent people from being vaccinated. On average, participants believed that they were less likely to become infected with the $\mathrm{A} / \mathrm{H} 1 \mathrm{~N} 1$ virus than to experience adverse side-effects from the vaccination. Accordingly, the threat of becoming infected was insufficient by itself to motivate action because the threat of side effects counterbalanced and, for many people, overwhelmed disease concern.

Moreover, these cognitive risk perceptions were mirrored by the affective risk perceptions: participants were more worried about adverse effects caused by the preventive measure than by the harm caused by the hazard itself. This is in line with previous studies conducted in Qatar, Hong Kong, and the UK $[11,21,39]$, demonstrating that both disease-related and vaccine-related risk perceptions were associated with vaccination acceptance. However, in these studies, disease- and vaccine-related risk perceptions were either assessed on different metrics or as two independent determinants of vaccination behavior, preventing an assessment of their joint impact on vaccination behavior.

Extending previous findings, the present results suggest that both factors operate in conjunction, i.e., if the hazard only induces a low level of concern and threat, the level of concern about the adverse side-effects of precaution is no longer important; people are generally unlikely to develop the intention to get vaccinated. However, even if the hazard induces substantial threat and worry, people are still likely to refrain from vaccination if they worry about side-effects. Thus, if the precaution is not perceived as being safe, clear disease-related risk perceptions might not even produce a behavioral effect. 
Another implication of the conjoint effects of disease- and vaccine related risk perceptions might be that the evaluation of the danger posed by adverse vaccine effects is dependent on the perceived danger of the hazard. Experimental studies show that probability estimates for negative events are systematically biased by their severity [40]. More serious adverse vaccine effects are likely to induce a more pronounced insensitivity to probability variations. Thus, the more serious the adverse effects, the more people overestimate even low probabilities and react adversely, despite the fact that it is unlikely these effects will occur [15]. Considering that the risk of side-effects is often communicated by verbal descriptors (e.g., very common, common, uncommon, rare, very rare [41]) which can induce a gross overestimation of risk [42], a negative acceleration in vaccination willingness might easily be induced. This effect might be further amplified by an 'omission bias' [43], a general tendency to rate objectively identical attributes (e.g., symptoms) less favorably when they are related to vaccine adverse events than to the disease [44]. In line with this notion, Brown et al. [44] found in an experimental study that parents would accept a higher risk of their child catching a (hypothetical) disease than they would of their child reacting to a vaccine. This omission bias is motivated by an asymmetrically anticipated regret that is the tendency to feel more regret for the consequences of one's actions (e.g., accepting a vaccine) than the consequences of inactions or 'fate' (e.g., remaining unvaccinated and catching the A/H1N1 virus). However, this is speculative.

It is likely that public confusion over the different swine-flu vaccines had amplified the perceived risk of adverse side-effects by the time the mass vaccination program was launched in Germany in October and November 2009 [45]. As Germany started its massvaccination program, it became public that the government had ordered a different vaccine for government officials and the military; namely Celvapan ${ }^{\circledR}$, which does not contain an adjuvant and was believed to have fewer side effects than Pandemrix ${ }^{\circledast}$. The widely circulated newspaper Bild accused the government of giving "second-class medicine" to regular German citizens [46]. The German government tried to deescalate the discussion, but skepticism never completely vanished. In addition, vaccination uptake might have been influenced by the tiered recommendation system. The Standing Committee for Vaccination (Ständige Impfkommission, STIKO) at the Robert-Koch Institute recommended at the beginning of October 2009 that everybody should get the vaccine but that initial doses should go to priority groups such as health care workers, pregnant women, and people with chronic health conditions [47]. Thus, the way the vaccination program was launched in Germany might have inflated the perception of potential sideeffects and deflated the perception of the danger inherent in the A/H1N1 infection. These aspects might also point to the changing dynamic over time. To ensure the effectiveness of health messages, the public must understand the message in a way that allows for both the retention and availability of the knowledge at the time of behavior implementation $[48,49]$.

\subsection{Limitations}

The present study is subject to a number of weaknesses. The disadvantage of our snowball technique for recruiting participants is limited population representativeness. That the vast majority of the participants had a high school degree clearly limits the generalizability of the findings (see also [25]); in particular, it is likely that numerical literacy was comparably high. In addition, participants volunteered and all data were self-reported, leading to social desirability and selection bias. As such, caution is required when extrapolating to the general population (see also [11]). The dropout between $\mathrm{T} 1$ and $\mathrm{T} 2$ was $28 \%$. While drop-out analyses did not show marked differences between the longitudinal sample and the drop-out sample in terms of perceived risk, sex, or education, participants may have dropped-out of the study due to lack of interest in the flu topic. As cognitive and affective risk perceptions were measured contemporaneously at $\mathrm{T} 1$, inferences about causality cannot be drawn. Nevertheless, the present data may indicate a pathway from cognitive to affective risk perceptions to intention (see [24] for longitudinal data). Alternatively, one could argue that affective risk perceptions occur first, triggering both cognitive risk perceptions and vaccination intentions. Finally, according to current health behavior theories, risk perception is only one of many predictors for health behaviors [7]. Thus, explaining the whole variance observed in the respective behavior is outside the scope of this study.

\section{Conclusion}

In the present longitudinal study, we examined whether vaccination behavior is driven by numerical-cognitive and/or affect-related risk perceptions. We found that high numericalcognitive risk perceptions, i.e.,. high perceived likelihood and severity of an influenza infection (hazard) and high perceived likelihood and severity of adverse vaccine side-effects (precaution) were associated with greater threat, concern, and worry and that these affective risk perceptions drove vaccination behavior. Therefore, numerical risk representations such as perceived likelihood and severity might represent necessary but insufficient self-referential knowledge that paves the way for preventive behaviors. Moreover, disease- and vaccine-related risk perceptions may function in a synergistic way. Even pronounced disease-related risk perceptions might be ineffective if we consider that people feel concerned and threatened by adverse vaccine side-effects. Thus, disease- and precaution-related risks need to be communicated conjointly in order to prevent biased risk estimations.

\section{Acknowledgements}

We would like to thank Helge Giese and David Schubring for their excellent support in data collection and scholarly insights. We thank Filipa Goncalves, Freda-Marie Hartung, and Angela Whale for their valuable support. This research was supported by the German Research Foundation (RE 1583/3-1; http://www.dfg.de/).

\section{References}

[1] World Health Organization. World now at the start of 2009 influenza pandemic. Available from: http:/www.who.int/mediacentre/news/ statements/2009/h1n1_pandemic_phase6.20090611/en/index.html [online 2009 , cited 07.10.12].

[2] Lau JTF, Yeung NCY, Choi KC, Cheng MYM, Tsui HY, Griffiths S. Factors in association with acceptability of A/H1N1 vaccination during the influenza A/H1N1 pandemic phase in the Hong Kong general population. Vaccine 2010;28:4632-7, http://dx.doi.org/10.1016/j.vaccine.2010.04.076.

(3) Wichmann $O$, Stocker $P$, Poggensee G, Altmann D, Walter D, Hellenbrand W, et al. Pandemic influenza $A(H 1 N 1) 2009$ breakthrough infections and estimates of vaccine effectiveness in Germany 2009 2010. Euro Surveill 2010;15(May (18)). PIl: 19561.

[4] Wilking H, Buda S, von der Lippe E, Altmann D, Krause G, Eckmanns T, et al. Mortality of 2009 pandemic influenza $A(H 1 N 1)$ in Germany. Euro Surveill 2010:15(December (49)). PII: 19741.

[5] Nichol KL. Efficacy and effectiveness of influenza vaccination. Vaccine 2008;26(Suppl. 4):D17-22.

[6] Walter D, Böhmer M, van der Heiden M, Reiter S, Krause G, Wichmann O. Monitoring pandemic influenza $A(H 1 N 1)$ vaccination coverage in Germany 2009/10 - results from thirteen consecutive cross-sectional surveys. Vaccine 2011;23:4008-12, http://dx.doi.org/10.1016/j.vaccine.2011.03.069

[7] Renner B. Schupp H. The perception of health risks. In: Friedman HS, editor. The Oxford handbook of health psychology. New York: Oxford University Press 2011. p. 639-67.

[8] Weinstein ND. Exploring the links between risk perceptions and preventive health behavior. In: Suls J. Wallston KA, editors. Social psychological foundations of health and ilness. Oxford: Blackwell: 2003. p. 22-53.

[9] Slovic P. The perception of risk. London: Earthscan Publications; 2000. 
[10] Brewer NT, Chapman GB, Gibbons FX, Gerrard M, McCaul KD, Weinstein ND. Meta-analysis of the relationship between risk perception and health behavior: the example of vaccination. Health Psychol 2007;26(2):136-45, http://dx.doi.org/10.1037/0278-6133.26.2.136.

[11] Liao Q Cowling BJ, Lam WWT, Fielding $\mathrm{R}$. Factors affecting intention to receive and self-reported receipt of 2009 pandemic (H1N1) vaccine in Hong Kong: a longitudinal study. PLoS One 2011;6(3):e17713. http://dx.doi.org/10.1371/journal.pone.0017713.

[12] Slovic P, Peters E. Risk perception and affect. Curr Dir Psychol Sci 2006;15(6):322-5, http://dx.doi.org/10.1111/j. 1467-8721.2006.00461.x.

(13) Schmälzle R, Schupp HT, Barth A, Renner B. Implicit and explicit processes in risk perception: neural antecedents of perceived HIV risk. Front Hum Neurosci 2011:5:43, http://dx.doi.org/10.3389/fnhum.2011.00043.

[14] Renner B, Schmalzle R, Schupp HT. First impressions of HIV risk: it takes only milliseconds to scan a stranger. PLoS One 2012;7(1):e30460, http://dx.doi.org/10.1371/journal.pone.0030460.

[15] Loewenstein GF, Weber EU, Hsee CK, Welch E. Risk as feelings. Psychol Bull 2001;127:267-86, http://dx.doi.org/10.1037/0033-2909-127-2.267.

[16] Chapman GB, Coups El. Emotional and preventive health behavior: worry, regret, and infuenza vaccination. Health Psychol 2006;25:82-90, http://dx.doi.org/10.1037/0278-6133.25.1.82.

[17] Liao Q Cowling B], Lam WWT, Fielding $R$. The influence of socialcognitive factors on personal hygiene practices to protect against influenzas: using modelling to compare Avian $\mathrm{A} / \mathrm{H} 5 \mathrm{~N} 1$ and 2009 Pandemic $A / H 1 N 1$ influenzas in Hong Kong. Int ] Behav Med 2010 http://dx.doi.org/10.1007/s12529-010-9123-8.

[18] Liao Q, Cowling B, Lam WT. Ng MW. Fielding R. Situational awareness and health protective responses to pandemic influenza $A(H 1 N 1)$ in Hong Kong: a cross-sectional study. PLoS One 2010;5(10):e13350, http://dx.doi.org/10.1371/journal.pone.0013350.

[19] Brown SL. Relationships between risk-taking behavior and subsequent risk perceptions. $\mathrm{Br} J$ Psychol 2005;96:155-64, http://dx,doi.org/10.1348/000712605X36703.

[20] Renner B, Schüz B, Sniehotta FF. Preventive health behavior and adaptive accuracy of risk perceptions. Risk Anal 2008;28:741-8, http://dx.doi.org/10.1111/j. 1539-6924.2008.01047.x.

[21] Alkuwari MG, Selim NA, Nazzal ZAS, Al-Nuaimi SA. Pandemic influenza A/H1N1 vaccination uptake among health care workers in Qatar: motivators and barriers. Vaccine 2011;29:2206-11. http://dx.doi.org/10.1016/j.vaccine.2010.08.093.

[22] Gaygisiz U, Gaygisiz E, Ozkan T, Lajunen T. Why were Turks unwilling to accept the A/H1N1 influenza-pandemic vaccination? People's beliefs and perceptions about the swine flu outbreak and vaccine in the later stage of the epidemic. Vaccine 2010;29:329-33, http://dx.doi.org/10.1016/j.vaccine.2010.10.030.

[23] Kwon $Y$, Cho H-Y, Lee $Y-K$, Bae G-R, Lee S-G, Relationship between intention of novel influenza $A$ (H1N1) vaccination and vaccination coverage rate. Vaccine 2011;29:161-5, http://dx.doi.org/10.1016/j.vaccine.2010.10.063.

[24] Reuter T, Renner B. Who takes precautionary action in the face of the new H1N1 influenza? Prediction of who collects a free hand sanitizer using a health behavior model. PLoS one 2011;6(7):e22130, http://dx.doi.org/10.1371/journal.pone.0022130.

[25] Jones $\mathrm{JH}$, Salathé $\mathrm{M}$. Early assessment of anxiety and behavioral response to novel swine-origin influenza A (H1N1). PLoS One 2009;4(12):e8032. http://dx.doi.org/10.1371/journal,pone.0008032.

[26] Cameron LD, Sherman KA, Marteau TM, Brown PM. Impact of genetic risk information and type of disease on perceived risk, anticipated affect, and expected consequences of genetic tests. Health Psychol 2009;28:307-16, http://dx.doi.org/10.1037/a0013947.

[27] Van D, McLaws ML. Crimmins J, Maclntyre CR, Seale H. University life and pandemic influenza: attitudes and intended behaviour of staff and students towards pandemic (H1N1) 2009. BMC Public Health 2010;10:130-8, http://www.biomedcentral.com/1471-2458/10/130

[28] Das Statistische Bundesamt. Zahlen und Fakten. Available at https://www.destatis.de/DE/ZahlenFakten/ZahlenFakten.html [cited 20.03.12].
[29] Croyle RT, Sande GN. Denial and confirmatory search: paradoxical consequences of medical diagnosis. J Appl Soc Psychol 1988:18:473-90, http://dx.doi.org/10.1111/j.1559-1816.1988.tb00030.x.

[30] Cohen J. A power primer. Psychol Bull 1992;112:155-9

[31] Arbuckle JL. Full information estimation in the presence of incomplete data. in: Marcoulides GA, Schumacker RE, editors. Advanced structural equation modeling. Mahwah: Erlbaum; 1996, p. 243-77.

[32] Preacher K], Hayes AF. Asymptotic and resampling strategies for assessing and comparing indirect effects in multiple mediator models. Behav Res Methods 2008;40:879-91, http://dx.doi.org/10.3758/BRM.40.3.879.

[33] Hayes AF, Beyond Baron, Kenny. Statistical mediation analysis in the new millennium. Commun Monogr 2009;76:408-20 http://dx.doi.org/10.1080/03637750903310360.

[34] Mathieu JE, Taylor SR. Clarifying conditions and decision points for meditational type inferences in organizational behavior. J Organ Behav 2006:27: $1031-56$.

[35] Aiken LS, West SG. Multiple regression: testing and interpreting interactions. Thousand Oaks: Sage; 1991.

[36) The Gallup Organization. Influenza H1N1 analytical report. Flash Eurobarometer. Available from: http://ec.europa.eu/public_opinion/flash/fl_258_en.pdf [March 2009; cited 07.10.12].

[37] Ditto PH, Pizarro DA, Epstein EB, Jacobson JA, MacDonald TK. Visceral influences on risk-taking behavior. J Behav Decis Making 2006;19:99-113, http://dx.doi.org/10.1002/bdm.520.

[38] Van Gelder JL, De Vries RE, Van der Pligt J. Evaluating a dual-process model of risk: affect and cognition as determinants of risky choice. J Behav Decis Making 2009;22:45-61. http://dx.doi.org/10.1002/bdm.610.

[39] Rubin G], Potts HWW. Michie S. Likely uptake of swine and seasonal flu vaccines among healthcare workers. A cross-sectional analysis of UK telephone survey data. Vaccine 2011;29:2421 -8, http://dx.doi.org/10.1016/j.vaccine.2011.01.035.

[40] Harris AJL, Corner A, Hahn U. Estimating the probability of negative events. Cognition 2009;110:51-64, http://dx.doi.org/10.1016/j,cognition.2008.10.006.

141) European Commission (EC). A guideline on the readability of the labe and package leaflet of medicinal products for human use. EC Pharmaceuticals Committee; 1998. Available from: http://www.alims.gov.rs/ download_eng/regulativa/gl981002.pdf [cited 07.10.12]

[42] Berry DC, Raynor DK, Knapp P. Bersellini E. Patients' understanding of risk associated with medication use. Drug Saf 2003;26(1):1-11.

[43] Baron], Ritov I. Protected values and omission bias as deontological judgments In: Bartels DM, Bauman CW. Skitka LJ, Medin DL, editors. Moral judgment and decision making. Ross BH, editor. The psychology of learning and motivation, vol. 50. San Diego, CA: Academic Press; 2009. p. 133-67.

[44] Brown KF, Kroll JS, Hudson M], Ramsay M, Green J, Vincent CA, et al. Omission bias and vaccine rejection by parents of healthy children: implications for the influence $A / H 1 N 1$ vaccination programme Vaccine 2010;28:4181-5, http://dx.doi.org/10.1016/j.vaccine.2010.04.012.

[45] Moore T. In Germany, a better vaccine for politicians? TIME. Available from: http:/www.time.com/time/health/article/0,8599,1932366,00.htm [2009 October 27, cited 07.10.12].

[46] Bild Merkel lässt sich impfen, Schäuble vermutlich nicht Available from: http://www.bild.de/politik/2009/regierung/experten-werfen-regierungzwei-klassen-medizin-vor-10142000.bild.html [2009 October 19, cited $07.10 .12]$.

[47] Robert Koch Institute. Neue Influenza: Ständige Impfkommission legt Impfempfehlungen vor. Available from; http:/ledoc.rki,de/documents/ rki_pressemitteilungen/rewqSYzOK6UvY/PDF/29SnLt4bSvQW2.pdf [online 2009 cited 07.10 .12 ]

[48] Reyna VF. Risk perception and communication in vaccination decisions: a fuzzy-trace theory approach. Spec Issue Vaccine - Int Vaccinat Risks: Vaccine 2012;25:3790-7, http://dx.doi.org/10.1016/j.vaccine.2011.11.070.

[49] Betsch C. Brewer NT, Brocard P, Davies P. Gaissmaier W, Haase $N$ et al. Opportunities and challenges of web 2.0 for vaccination decisions. Spec issue Vaccine - Int Vaccinat Risks: Vaccine 2012;25:3727-33. http://dx.doi.org/10.1016/j.vaccine.2012.02.025. 